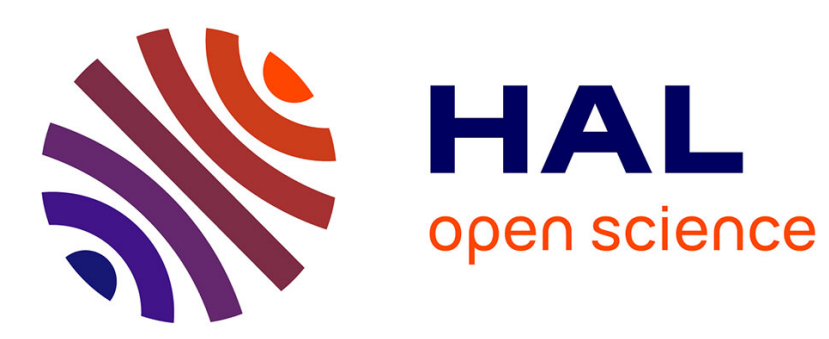

\title{
Extreme Financial Cycles
}

Bertrand Candelon, Guillaume Gaulier, Christophe Hurlin

\section{To cite this version:}

Bertrand Candelon, Guillaume Gaulier, Christophe Hurlin. Extreme Financial Cycles. 2012. halshs00769817

\section{HAL Id: halshs-00769817 https://shs.hal.science/halshs-00769817}

Preprint submitted on 3 Jan 2013

HAL is a multi-disciplinary open access archive for the deposit and dissemination of scientific research documents, whether they are published or not. The documents may come from teaching and research institutions in France or abroad, or from public or private research centers.
L'archive ouverte pluridisciplinaire HAL, est destinée au dépôt et à la diffusion de documents scientifiques de niveau recherche, publiés ou non, émanant des établissements d'enseignement et de recherche français ou étrangers, des laboratoires publics ou privés. 


\title{
Extreme Financial cycles ${ }^{\underline{4}}$
}

\author{
B. Candelon ${ }^{\text {b,* }}$, G. Gaulier ${ }^{\mathrm{a}}$, C. Hurlin ${ }^{\mathrm{b}}$ \\ ${ }^{a}$ University Maastricht, Department of Economics, P.O. Box 616, MD6200 Maastricht, \\ The Netherlands. \\ ${ }^{b}$ Banque de France, Paris, France. \\ ${ }^{c}$ University of Orléans, Laboratoire d'Economie d'Orléans (LEO), France.
}

\begin{abstract}
This paper proposes a new approach to date extreme financial cycles. Elaborating on recent methods in extreme value theory, it elaborates an extension of the famous calculus rule to detect extreme peaks and troughs. Applied on United-States stock market since 1871, it leads to a dating of these exceptional events and calls for adequate economic policies in order to tackle them.

Cet article élabore une nouvelle méthodologie de datation des cycles financiers extrêmes. S'appuyant sur la théorie des valeurs extrêmes, il étend la "calculus rule" afin de détecter les pics et les creux exceptionnels. Appliquée sur des séries financières américaines depuis 1871, cette méthode permet de mieux appréhender les mouvements extrmes et d'y apporter le cas écheant les réponses les plus adéquates.
\end{abstract}

Keywords: Financial extreme cycles; Extreme value theory; cycles financiers extrm̀es; théorie des valeurs extrèmes.

JEL codes: C22; G00.

\section{Introduction}

Since the seminal paper of Burns and Mitchell (1947), the economic literature has proposed numerous methodologies ${ }^{1}$ to detect peaks and troughs in order to date the recession and expansion phases of the business cycle. Such a dating

\footnotetext{
${ }^{\sqrt{4}}$ We are indebted to Mélika Bensalem and Frédérique Bec, the guest editors of the Revue d'Economie Politique, as well as two anonymous referees for their constructive comments and suggestions. We also thank the seminar participants to the "Journé en l'honneur de PierreYves Hénin". Usual disclaimers apply.

*Corresponding author.

Email addresses: b.candelon@maastrichtuniversity.nl (B. Candelon), (G. Gaulier), christophe.hurlin@univ-orleans.fr (C. Hurlin)

${ }^{1}$ The Bry and Boschan (1971) approach remains the most famous one.
} 
delivers practitioners with the adequate information to correctly time economic policies, insuring hence an optimal stabilization effect.

Nevertheless, academic literature has neglected two important dimensions. First, similarly to economic activity, stock markets also exhibit periods of persistent rises or falls, i.e. so-called "bulls" and "bears". While it has been recognized by the financial practitioners for a long time, it has attracted the attention from the academic community only in the recent past. Pagan and Sossounov (2003), and Candelon et al. (2008) scan the cross country synchronization of bull and bear phases. Gómez Biscarri and Pérez de Gracia (2002), and Edwards et al. (2003) focus on the structural change in cyclical stock market synchronization. Chen (2009) considers bear markets as a key variable to forecast, and investigates the role of macroeconomic variables to predict bear markets. Second, a bull (resp. a bear) phase can be sufficiently rare to be classified as extreme asking for exceptional accommodating economic policies. This is in particular the case during financial crises, where fluctuations on the stock markets are severe. The analysis of exceptional bulls and bears has thus only been scarcely investigated (Candelon and Henin, 1995 or Candelon and Metiu, 2010 to name but a few).

This paper proposes to tackle both issues, offering a new approach to evaluate exceptional parts of the financial cycles, based on the extreme value theory (EVT), in particular on the paper of Hartmann et al. (2004).

In Section 2, the behavior of extreme phases of financial cycles is scrutinized. It begins with the definition of financial cycles' peak and troughs. The new framework to measure of extreme phases can then be presented. Elaborating on EVT, it aims at estimating two thresholds beyond (resp. below) which an extreme bull (resp. bear) can be characterized. It is noticeable that such an approach relies on the conditional probability of exceeding a upper (resp. lower) threshold, differing hence on methods considering unconditional measures. Beyond being very easy to implement, our approach presents also the advantage to allow for different thresholds for exceptional bulls and bears, authorizing hence for asymmetry among the extreme financial cyclical phases. Section 3 is devoted 
to the empirical analysis where the extreme phases of the U.S. stock market are investigated, whereas Section 4 concludes.

\section{Extreme Financial Cycles}

\subsection{Characterizing financial cycles}

Let us consider a series of stock market prices $\left(y_{t}\right)$ and its associated real financial returns $\left(r_{t}=\Delta y_{t}\right)$. The simplest rule to detect a peak (resp. a trough) in considering as a peak (resp. a trough) of a series $r_{t}$ at time $t$, if $r_{t}>0$ and $r_{t+1}<0$ (resp. $r_{t}<0$ and $r_{t+1}>0$ ). This approach is often referred as the calculus rule. In other words, the existence of a turning point is associated with a change in the sign of the first derivative. It is possible to illustrate graphically this rule where the clouds of points are represented in a space $\left(r_{t}, r_{t+1}\right)$. For ease of convenience, $\left(r_{t}, r_{t+1}\right)$ are drawn from two independent standard normal distributions and have a dimension $T=1,000$.

It turns out that potential peaks are located in the south-east quadrant whereas potential trough are in the north-west $(\mathrm{N}-\mathrm{W})$ quadrant. In the two remaining quarters, i.e. south-west $(\mathrm{S}-\mathrm{W})$ and north-east $(\mathrm{N}-\mathrm{E})$, there is no change in the first derivative, which is identical. An acceleration is nevertheless

detectable if the angle is larger the $45^{\circ}$, as $\left|r_{t+1}\right|>\left|r_{t}\right|$. In such a case, a situation of excess growth (resp. excess loss) can be observed in the north-east (N-E) (resp. south-west, S-E, quadrant). This representation is often labeled as the clockwise approach.

\subsection{Characterizing extreme financial cycles}

Turning points are then characterized by the quadrant they are belonging to. Besides, the distance from the origin indicates there strength. Typically, the further they are from the origin, the most severe would be the cycle phase associated to the turning point. Formally, the distance form the origin can be written as $d_{t}=\sqrt{\left(r_{t}^{2}+r_{t+1}^{2}\right)}$, and then $d_{t}$ increases with $\left|r_{t+1}\right|$ and $\left|r_{t}\right|$. 


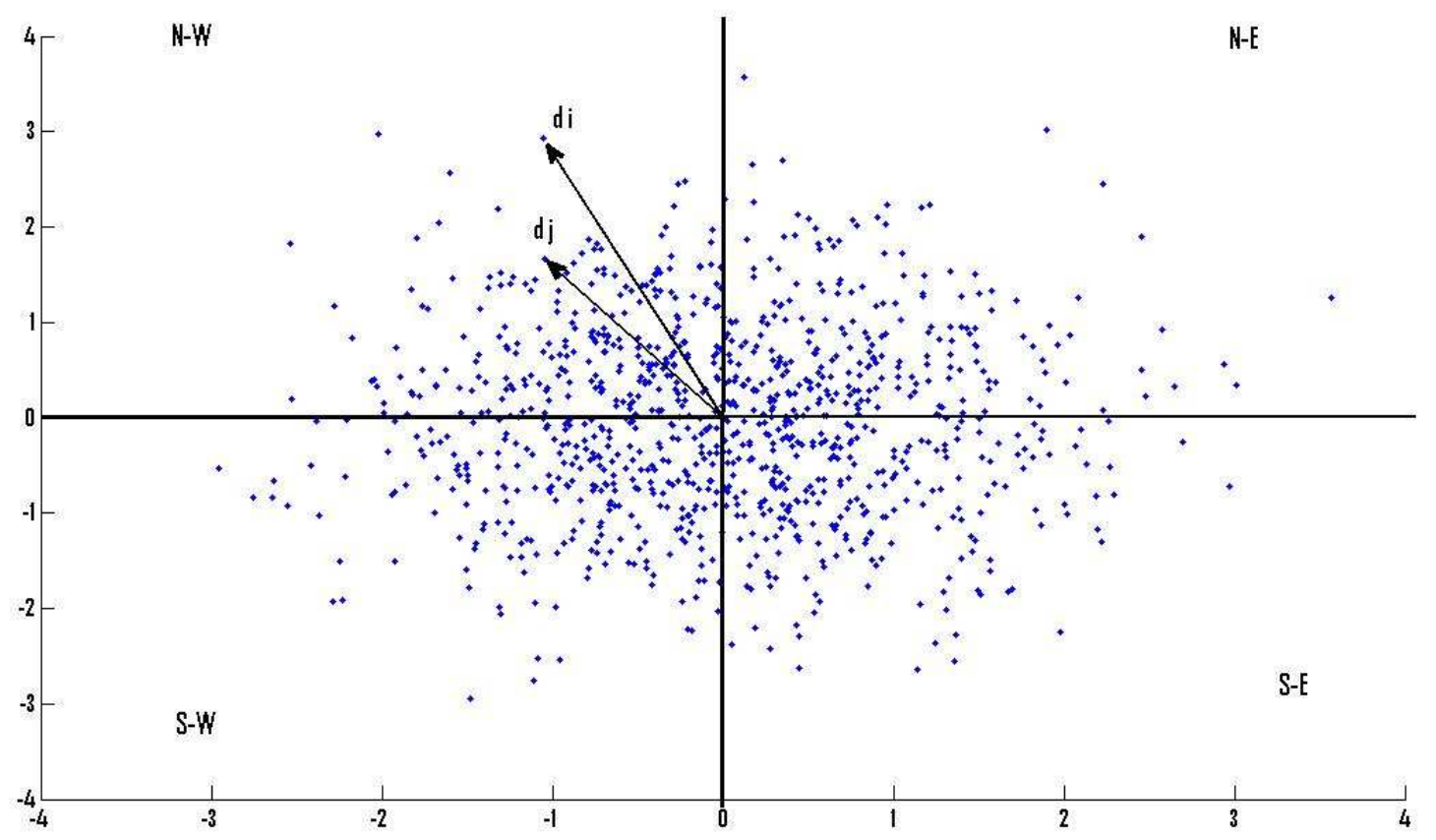

Figure 1: Clouds of points issued from two independent normal distributions. 
In Figure 1, two troughs $i$ and $j$ are considered, and it is immediately noticeable that $d_{j}<d_{i}$ indicating that the turning point $i$ is more extreme than the turning point $j$. Such a result can be drawn even if $r_{i, t}=r_{j, t}$, highlighting that the distance measure has a conditional dimension. Empirically, it can be rewritten in terms of conditional probability. The probability of occurrence of $i\left(P\left(r_{t}<q_{1}, r_{t+1}>q_{2}\right)\right)$ is lower than the one of $j$. A turning point will be considered as extreme if for the given thresholds $\left(q_{1}, q_{2}\right)$, this joint-probability is lower than $\alpha$ an criterion of severity, which is generally set up to $5 \%$ or $1 \%$. The thresholds can be endogenously obtained via the following minimization problem:

$$
\operatorname{Min}_{q_{1}, q_{2}} P\left(r_{t}<q_{1}, r_{t+1}>q_{2}\right)=\alpha \text {. }
$$

It is straightforward to notice that the set of points satisfying (1) is infinite and corresponds to the values $q_{1}, q_{2}$ defining the contour at $\alpha \%$ of the cloud of points. $^{2}$ The contour line at $5 \%$ is represented in Figure 2 for the two independent standard normal distributions. It is possible to see that the contour line, which is usually an ellipse, becomes a circle when considering two independent normal distributions for $r_{t}$ and $r_{t+1}$. When returns would depart from the i.i.idness hypothesis, the contour line would not be a circle anymore. For example, in a case of a simple $\mathrm{AR}(1)$ process with a positive coefficient, the ellipse will be oriented from the south-west to the north-east.

Additional constraints are then required to obtain an unique solution. We therefore imposed that each unconditional probability should be also extreme $P\left(r_{t}>q_{1}\right)=P\left(r_{t+1}<q_{2}\right)=p$. Graphically, such a constraint consists in imposing a minimum angle on the $\mathrm{x}$ - and $\mathrm{y}$-axis, in order to reduce the possible set of $q_{1}, q_{2}$. Hence, the program boils down to:

\footnotetext{
${ }^{2}$ The reader can also consider the contour line as the frontier out of which $\alpha \%$ of the points are left out.
} 


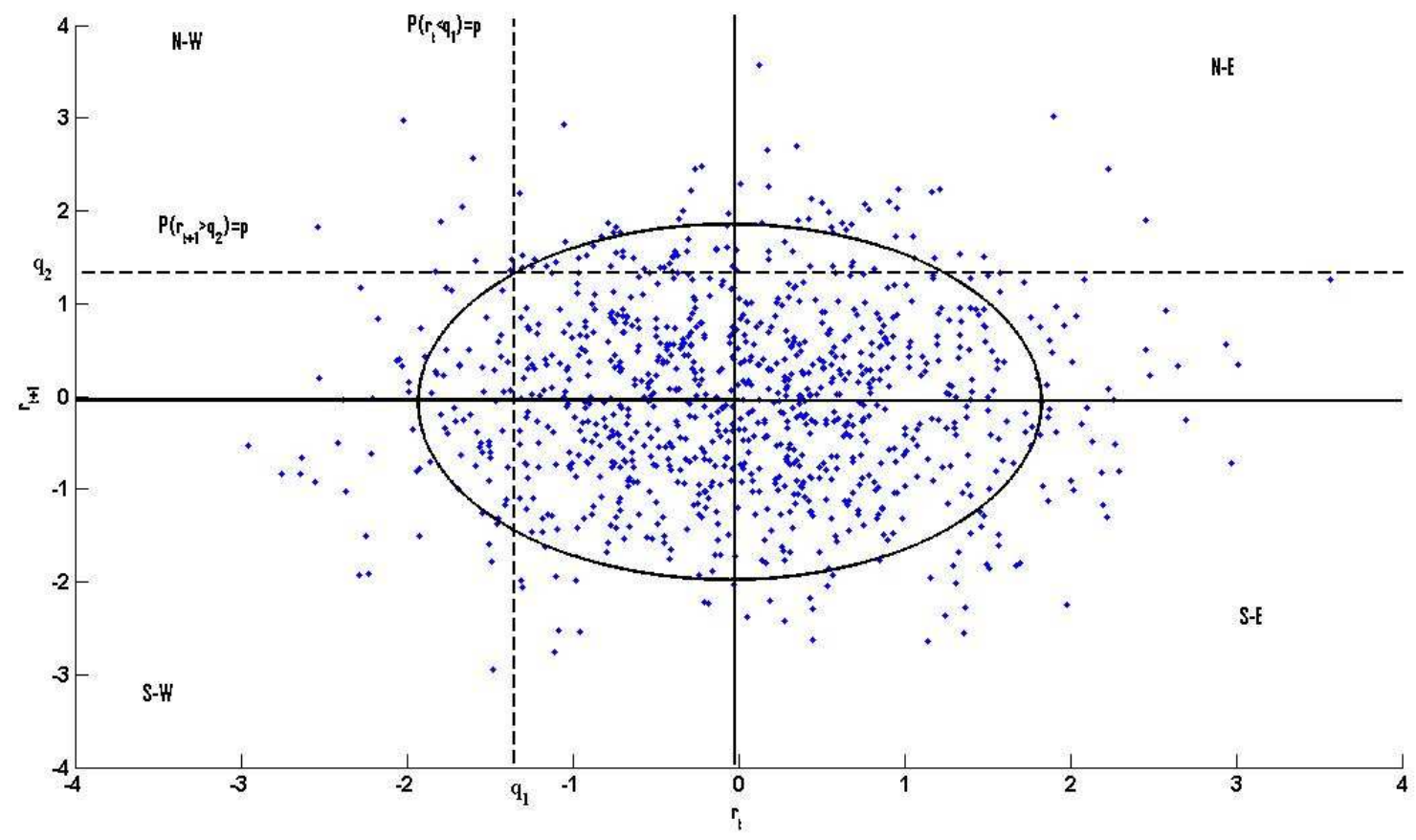

Figure 2: Contour line and measure of severity. 


$$
\operatorname{Min}_{\left(p, q_{1}, q_{2}\right)} \text { s.t. }\left\{\begin{array}{l}
P\left(r_{t}<q_{1}\right)=p \\
P\left(r_{t+1}>q_{2}\right)=p \\
P\left(r_{t}<q_{1}, r_{t+1}>q_{2}\right)=\alpha .
\end{array}\right.
$$

The optimal thresholds $q_{1}^{*}$ and $q_{2}^{*}$ are then located on Figure 2 and turn out to be symmetric as we are considering two independent symmetric distributions. The troughs are located thus in the North-West area delimited by $q_{1}^{*}$ and $q_{2}^{*}$. Straetmans et al. (2004) elaborates a statistical framework to test for such a hypothesis of symmetry.

Similarly, it is possible to set up program for extreme peak as follows:

$$
\text { Peak: } \operatorname{Min}_{\left(p, q_{1}, q_{2}\right)} \text { s.t. }\left\{\begin{array}{l}
P\left(r_{t}>q_{1}\right)=p \\
P\left(r_{t+1}<q_{2}\right)=p \\
P\left(r_{t}>q_{1}, r_{t+1}<q_{2}\right)=\alpha .
\end{array}\right.
$$

\section{Empirical example}

To illustrate the outlined method, we consider the historical yearly database for U.S. Stock Price Data $\left(y_{t}\right)$ proposed by Shiller ${ }^{3}$ covering the period 18712011. Data are considered on yearly frequency in order to avoid specific problems associated with high frequency time series, such as conditional heteroscedasticity. ${ }^{4}$ Besides, we consider that a fluctuation can be defined as bulls or bears only if its length exceeds a year. Two series are considered: First the real stock price (SP), defined as the ratio of the stock market composite index over the Consumer price index and the Price Earning ratio (PER). They are represented on Figures 3 a) and b).

Applying the program defined by (2) to (3), we obtain the estimates for $q_{1}^{*}$ and $q_{2}^{*}$ for $\alpha=(1 \%$ and $5 \%){ }^{5}$ They are reported in Table 1 and the corresponding periods of extreme peaks and troughs are gathered in Table 2.

\footnotetext{
${ }^{3}$ Data correspond to an Update of those presented in Chapter 26 of Market Volatility, R. Shiller, MIT Press, 1989, and Irrational Exuberance, Princeton 2005. Time series are freely available at the following address : http://www.econ.yale.edu/ shiller/data.htm.

${ }^{4} \mathrm{~A}$ potential extension of this method could be devoted to assess the properties of our approach in the presence of such patterns.

${ }^{5}$ Programs are freely available at www.runmycode.com.
} 


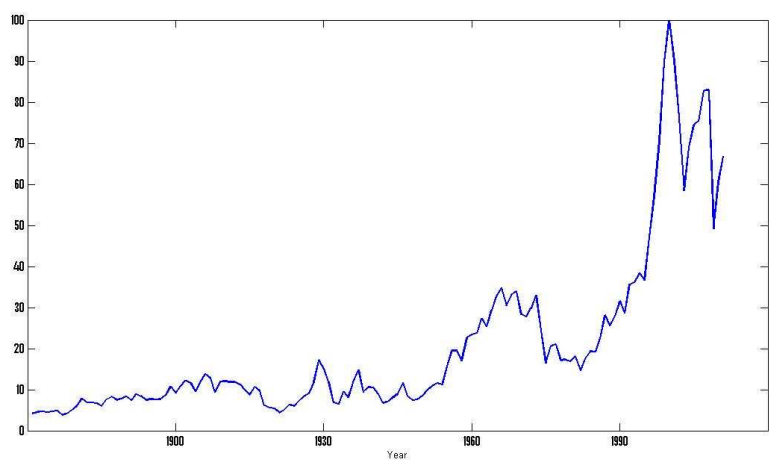

(a) Real Stock Prices

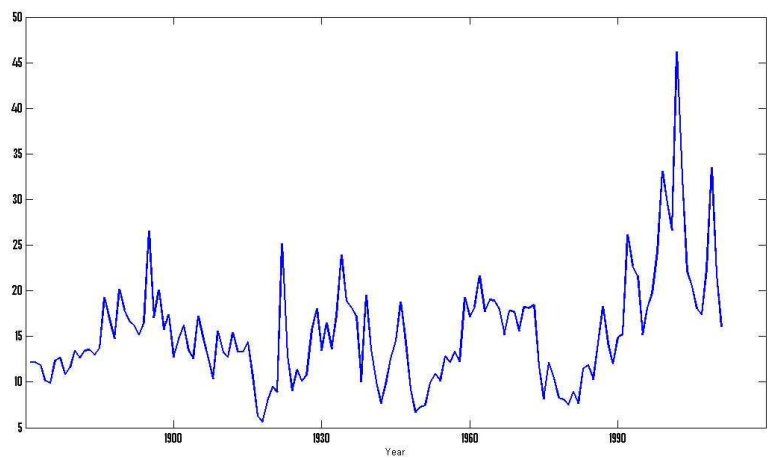

(b) Price Earning Ratio

Figure 3: Historical data, United-States, 1871-2011

Table 1: Thresholds for $r_{t}$ Real Stock Prices (SP)

\begin{tabular}{ccccccc}
\multicolumn{3}{c}{$\alpha=5 \%$} & \multicolumn{3}{c}{$\alpha=1 \%$} \\
\hline & $\mathrm{p}$ & $q_{1}^{*}$ & $q_{2}^{*}$ & $\mathrm{p}$ & $q_{1}^{*}$ & $q_{2}^{*}$ \\
\hline Trough & 0.207 & -1.326 & 2.627 & 0.029 & -13.768 & 10.466 \\
Peak & 0.193 & 2.741 & -1.392 & 0.136 & 3.532 & -2.466 \\
\hline \hline \multicolumn{3}{c}{ Price Earning Ratio (PER) } \\
\hline \multicolumn{3}{c}{$\alpha=5$} \\
\hline Trough & 0.221 & -2.473 & 2.600 & 0.171 & -3.529 & 2.990 \\
Peak & 0.136 & 3.937 & -3.925 & 0.021 & 10.899 & -11.761 \\
\hline
\end{tabular}


Table 2: Exceptional Peaks and troughs

\begin{tabular}{|c|c|c|c|c|c|c|c|c|c|}
\hline & & & & Real & $\begin{array}{l}\alpha=5 \\
\alpha=5\end{array}$ & $\begin{array}{l}\text { ices }(\mathrm{S} \\
0\end{array}$ & & & \\
\hline Peak & 1930 & 1935 & 1938 & 1946 & 1963 & 1974 & 1988 & 1991 & 2001 \\
\hline Trough & 1936 & 1959 & 1964 & 1976 & 1983 & 1992 & 1996 & 2004 & 2010 \\
\hline & & & & & $\alpha=1$ & & & & \\
\hline Peak & 1988 & 1991 & 2001 & & & & & & \\
\hline Trough & 2004 & 2010 & & & & & & & \\
\hline & & & & ice Ea & $\begin{array}{l}\text { ning } \\
\alpha=\end{array}$ & $\begin{array}{l}\text { atio }(\mathrm{F} \\
y_{0}\end{array}$ & R) & & \\
\hline Peak & 1886 & 1923 & 1935 & 1940 & 1947 & 1988 & 2003 & 2010 & \\
\hline Trough & 1897 & 1931 & 1933 & 1939 & 1968 & 1976 & 1996 & 2002 & \\
\hline & & & & & $\alpha=1$ & & & & \\
\hline Peak & 1923 & 2003 & & & & & & & \\
\hline Trough & 1897 & 1939 & 1976 & & & & & & \\
\hline
\end{tabular}

We first notice that the estimated thresholds are decreasing with $\alpha$, the measure for severity, matching the idea that the more conservative the severity criterion is, the higher the thresholds are and the less numerous the exceptional peaks/troughs are detected. ${ }^{6}$ The unconditional probability $p$ presents an opposite evolution, corroborating its positive relationship with the severity criterion.

Second, it turns out that thresholds $q_{1}^{*}$ and $q_{2}^{*}$ present almost the same absolute value but opposite sign (except for SP at 5\%), supporting hence the symmetry hypothesis. ${ }^{7}$ Exceptional peaks and troughs conditions are then identical, indicating that their number should not differ too much. This is what we observe in Table 2 , where we detect 8 or 9 exceptional peaks and troughs at $5 \%$ and 2 or 3 at $1 \%$.

Third, the interpretation of the extreme financial cycles since 1871 reveals interesting features: For both series (SP and PER) extreme peaks are very frequent during the first part of the $X X^{\text {th }}$ century 1920-1946 (4 out of 9 extremes

\footnotetext{
${ }^{6} \mathrm{~A}$ similar pattern is observed when considering a $10 \%$ threshold. For sake of space, this result is not reported but is available from the authors upon request.

${ }^{7}$ A formal test a la Straetmans et al (2004) could be performed to formally test for such an hypothesis.
} 
peaks are detected for SP and 4 out of eight for PER) and since 1987 (3 out of 9 for both series) when $\alpha$ is fixed to $5 \%$. The exceptional peak recently observed corresponds to the well known high tech bubble, usually called dot.com bubble, whereas the peaks in the early 1900's are related to the great depression fluctuations. The difference between series appear when considering a $1 \%$ threshold. In such a case, peaks in SP are all located in the recent years whereas 1923 is also extreme for the price earning ratio. This stylized fact is straightforward when looking at Figures 3 a) and b): The real stock price skyrocketed last 30 years, where the price earning ratio remains stable. This discrepancy is also noticeable when analysing exceptional troughs at 1\%. Exceptional troughs are following a different path. They appear to be more severe in the recent years (1988, 1991, and 2001) for SP but not for PER (1897, 1939 and 1976). This stylized fact constitutes an interesting feature of the recent years: extreme stock prices associated with relatively price earning ratios. Besides, Such it has consequence in term of economic policy, as it would suggest that recent the troughs in SP are rather extreme and should be tackled using specific stabilization policies and not the traditional ones.

\section{Conclusion}

This paper proposes a deeper analysis of extreme financial cycles. Elaborating on recent method in extreme value theory, it proposes an extension of the famous calculus rule to detect extreme peaks and troughs. This method presents also some interesting potential byproducts as the detection of outliers in stationary time series. In the present paper, it is applied on United-States stock market since 1871. The dating of the exceptional peaks and troughs clearly indicates that the last thirty years are extreme for real stock prices but to a much lesser extend for Price Earning Ratio. This discrepancy constitutes an interesting feature of the recent years. Such findings also reveal that traditional stabilization policies implemented to limit the occurrence of extreme bulls or bears in stock prices fails. It thus paves the way for future research analysing optimal stabilization policies. 


\section{References}

Bry, G. and Boschan, C. (1971) Cyclical Analysis of Time Series: Selected Procedures and Computer Programs (New York: NBER).

Burns, A.F. and Mitchell, W.C. (1947) Measuring Business Cycles (New York: NBER).

Candelon, B. and Hénin, P.Y. (1995) "La recession des Annees Quatre-Vingt Dix a-t-elle ete Exceptionnelle?" Economie et Prevision, 120(4), 51-71.

Candelon, B., Piplack, J. and Straetmans, S. (2008) "On Measuring Synchronization of Bulls and Bears: The Case of East Asia", Journal of Banking and Finance, 32, 1022-1035.

Candelon, B. and Metiu, N. (2010) "Testing for Exceptional Bulls and Bears: A Non-Parametric Perspective", Meteor Working Paper.

Edwards, S., Gomez Biscarri, J., Perez de Gracia, H.F., (2003) "Stock Market Cycles, Financial Liberalization and Volatility", Journal of International Money and Finance 22, 925-955.

Gomez Biscarri, J., and Perez de Gracia, H.F., (2002) "Bulls and Bears: Lessons from some European Countries", Working paper.

P. Hartmann, Straetmans, S., and de Vries, C., (2004) Asset Market Linkages in Crisis Periods, Review of Economics and Statistics, 86(1), 313-326.

Pagan, A.P., and Sossounov, K.A., (2003) A Simple Framework for Analysing Bull and Bear Markets, Journal of Applied Econometrics 18, 233-246. 